\title{
Clinical features in four patients with Angelman syndrome resulting from paternal uniparental disomy
}

\author{
A Smith, R Marks, E Haan, J Dixon, R J Trent
}

Department of Cytogenetics, New Children's Hospital, Hawkesbury Road, Westmead, NSW 2145, Australia

A Smith

Developmental

Paediatrics, Starship

Children's Health,

Auckland, New

Zealand

R Marks

Department of Medical Genetics, Women and Children's Hospital, Adelaide, Australia

E Haan

\section{Department of Genetics and Paediatrics, Wellington Hospital, New Zealand J Dixon}

\section{Department of Molecular Genetics, Royal Prince Alfred Hospital, Sydney, Australia \\ R J Trent}

Correspondence to: Dr Smith.

Received 27 June 1996 Revised version accepted for publication 4 December 1996

\begin{abstract}
Angelman syndrome (AS) is a complex neurological disorder with different genetic aetiologies. It is not known whether the clinical features vary depending on the genetic mechanism. We report four patients with AS owing to uniparental disomy (UPD). There were two males and two females, with a mean age of 8 years (range 7 to 11 years). All patients had a happy disposition, hyperactive behaviour, and the characteristic facial phenotype of AS, but in three there was a normal head circumference, two had epilepsy, ataxic movements were mild in three, the mean age of onset of walking was 2.4 years, and there was some sign language in all four patients. Our cases add further weight to the previously reported impressions of a milder phenotype in cases of AS resulting from UPD than in deleted AS patients. Patients suspected of having AS, but who are considered atypical, warrant DNA testing.

$(\mathcal{M}$ Med Genet 1997;34:426-429)
\end{abstract}

Keywords: chromosome 15(q11-13); epilepsy; intellectual disability; imprinting

Angelman syndrome (AS) is a severe neurodevelopmental disorder with a complex genetic aetiology. Since the first report of three children, ${ }^{1}$ the clinical phenotype has become more defined and comprises severe intellectual disability, epilepsy, lack of speech, ataxic movements, outbursts of inappropriate laughter, large mouth and chin, microcephaly, an abnormal EEG, and hypopigmentation in some patients. ${ }^{23}$ The phenotype may be variable, and cases have been described as atypical. ${ }^{4}$ The availability of DNA testing has enabled a genetic classification of AS. Four groups are now recognised: (1) maternal deletions of chromosome 15(q11-13) (about $70 \%$ of cases), (2) paternal uniparental disomy of chromosome 15 (about 2\%), (3) an abnormality in the imprinting process (about 3\%), and (4) a mutation affecting a putative AS gene in the remainder. ${ }^{5}$ The chromosome 15(q11-13) region also contains the Prader-Willi syndrome (PWS) locus. This region is subject to genomic imprinting, whereby the expression of the gene(s) is dependent on the parent of origin. In AS the locus on the paternally derived chromosome 15 is imprinted and cases with UPD have inherited both copies of the chromosome
15 from the father and none from the mother. The parental origin is the reverse in PWS.

Cases of AS resulting from UPD are rare and only a few reports have been published with detailed clinical descriptions. ${ }^{7-14}$ In this report we describe four new patients with AS resulting from paternal UPD, to broaden the knowledge of this genetic type.

\section{Methods}

PATIENTS

Patients with the clinical suspicion of AS were referred from Australia and New Zealand for genetic testing under a research grant protocol, approved by the institutional ethics committee. ${ }^{15}$ Clinical information was obtained from the data sheet accompanying each referral, correspondence with referring doctors, hospital records, baby health centre records, and parent interviews. All were last reviewed in March 1996.

DNA ANALYSIS

Molecular studies (performed during 1991 to 1994) used standard techniques. ${ }^{15} 16$ Polymorphism analysis was performed with probes for loci from within the PWS/AS region (D15S18, D15S9, D15S11, D15S13, D15S128, D15S10, D15S113, D15S97 (GABRB3), D15S98, D15S108, D15S12) and outside the region distally on chromosome 15q (D15S24, ACTC, THBS1, D15S87, D15S86). Informative polymorphisms showing UPD in the four patients are shown in table 1 .

\section{Results and discussion}

We have presented the features of four patients with AS resulting from paternal UPD (figs 1, 2, and 3 ). All patients showed a characteristic facial appearance with large mouth and chin, a happy disposition, outbursts of laughter, hyperactive behaviour, no speech, and severe intellectual disability. Drooling and mouthing were present in all cases, but were not pronounced features. Additional clinical information for each of the four patients with UPD is given in table 2A. The mean age of diagnosis was 6.25 years and mean age at last review was 8.25 years. All patients were ataxic but in three (cases 28, 29, and 31) the ataxia was mild and most evident when excited. The mean age of onset of walking was 2.4 years, with all walking by 3 years of age. Epilepsy (onset at 1.5 and 4.5 years) was present in two patients. Two patients, at 7 and 8 years of age, had never had a seizure of any type and were not on anticon- 
Table 1 Pattern of informative DNA markers for the four patients with UPD

\begin{tabular}{|c|c|c|c|c|c|c|}
\hline \multirow[b]{2}{*}{ Family } & \multicolumn{6}{|c|}{ DNA probe } \\
\hline & D15S11 & D15S13 & D15S113 & D15S97 & $D 15 S 98$ & D15S108 \\
\hline Patient 28 & b & $\mathrm{d}$ & & & c & \\
\hline Mother & c & $\mathrm{bc}$ & & & $a b$ & \\
\hline Father & $a b$ & ad & & & $\mathrm{cd}$ & \\
\hline Patient 29 & & $\mathrm{~b}$ & $\mathrm{~d}$ & & c & \\
\hline Mother & & c & $\mathrm{bc}$ & & $a b$ & \\
\hline Father & & $a b$ & ad & & $\mathrm{cd}$ & \\
\hline Patient 30 & & & & & c & c \\
\hline Mother & & & & & $a b$ & $a b$ \\
\hline Father & & & & & ac & ac \\
\hline Patient 31 & ac & & $a b$ & a & & $\mathrm{a}$ \\
\hline Mother & $\mathrm{b}$ & & c & $\mathrm{b}$ & & $\mathrm{b}$ \\
\hline Father unknown & & & & & & \\
\hline
\end{tabular}

vulsant therapy. The EEG was abnormal in $3 / 3$ patients tested. The characteristic slow spike and wave forms associated with $\mathrm{AS}^{17}$ were reported in these tracings. One patient (29) was clearly hypopigmented compared to his family (fig 2). He did not have albinism, but hypopigmentation could occur with isodisomy UPD if the patient received two copies of a mutant pigmentation gene from his father. This was not tested here. Both height and head circumference was normal for three patients, while one was short and one was microcephalic. Head circumference and height centiles were concordant for two patients, but discordant in two (patients 28 and 31 ). In two patients, the weight was over the 50 th centile.

We compared our data with 10 other reported cases of AS resulting from UPD (table 2B). Varying details are presented with scant clinical information in some. The mean age of these reported cases was 7.5 (range 3-30) years, similar to our cohort (8.25 years). The head circumference was normal in 10/14 (71.5 \%) patients reported. Including our data, 4/14 patients had microcephaly, a frequency of $28.5 \%$. Over all, height was on the 3rd centile or less in $3 / 13(23 \%)$ patients and normal in $10 / 13(77 \%)$. Weight was over the 50th centile in $7 / 11(64 \%)$ of patients. In the reported cases, seizures had occurred in $3 / 8$ patients which, when combined with our data,

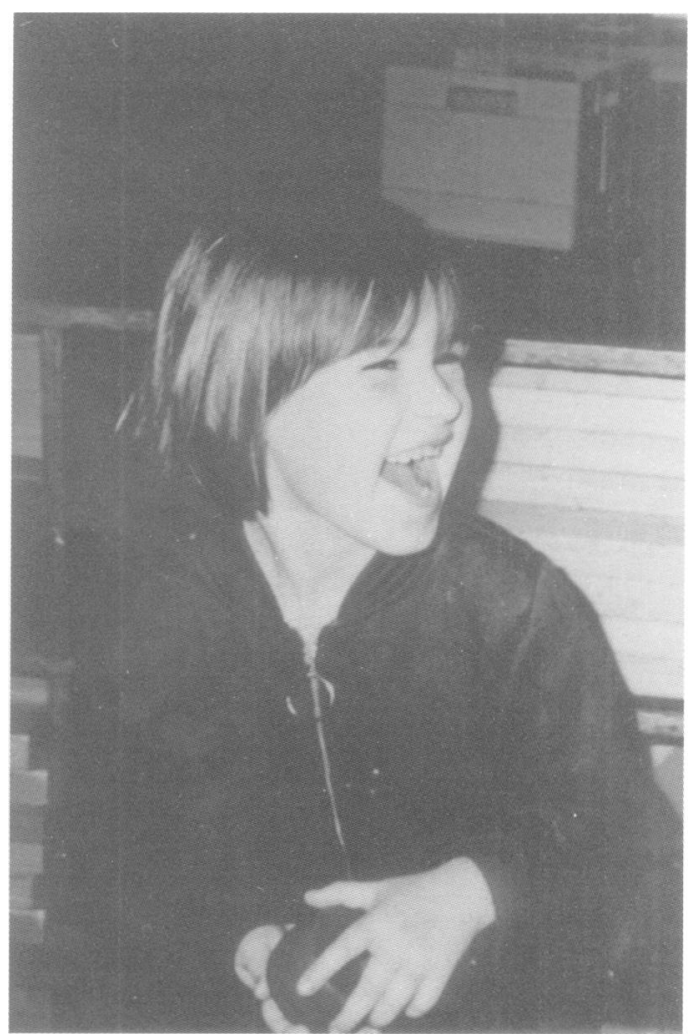

Figure 1 Patient 28 aged 7 years.

shows that the occurrence of epilepsy was $5 / 12$ patients $(42 \%)$. All patients tested had an abnormal EEG. Ataxia was mild in 4/13 (31\%) ambulant patients. One patient was not ataxic. $^{12}$

The mean paternal age for the combined data on nine cases was slightly raised at $\mathbf{3 2 . 5}$ years. The mean maternal age for the combined data on 11 cases was normal at 28.25 years. This is of interest as mechanisms leading to paternal UPD include paternal meiotic nondisjunction followed by trisomic rescue, isochromosome formation, and maternal nondisjunction followed by monosomy rescue. ${ }^{18}$ One of our patients had a translocation which, combined with the reported studies (table 2),

Table 2 Patient data (A) and published clinical descriptions of Angelman syndrome owing to paternal UPD (B)

\begin{tabular}{|c|c|c|c|c|c|c|c|c|c|c|c|c|c|c|c|}
\hline$I D$ & $S$ & $A D / R$ & $B W$ & $\begin{array}{l}\text { HCR } \\
\text { centile }\end{array}$ & $\begin{array}{l}H t R \\
\text { centile }\end{array}$ & $\begin{array}{l}\text { WtR } \\
\text { centile }\end{array}$ & $E$ & $E E G$ & $W$ & $A t$ & $P$ & $S L$ & $M A$ & $P A$ & $K$ \\
\hline \multicolumn{16}{|l|}{$A$} \\
\hline 28 & $\mathrm{~F}$ & $4 / 7$ & 3700 & 25 & $75^{\star}$ & 50 & No & abn & 2 & $\mathrm{~m}$ & fam & 10 & 22 & 25 & $\mathrm{~N}$ \\
\hline 29 & $\mathbf{M}$ & $7 / 8$ & 4000 & 25 & 25 & 10 & No & ND & 2 & $\mathrm{~m}$ & $\mathrm{H}$ & 15 & 28 & 32 & $\mathrm{~N}$ \\
\hline 30 & $\mathrm{~F}$ & $9 / 11$ & $2180 \dagger$ & 2 & 3 & $>97$ & 1.5 & $a b n$ & 2.5 & Yes & fam & 8 & 25 & 31 & $\mathrm{~N}$ \\
\hline 31 & $M$ & $5 / 7$ & 3420 & 25 & 50 & 90 & 4.5 & $a b n$ & 3 & $\mathrm{~m}$ & fam & 35 & 19 & NK & $t$ \\
\hline \multicolumn{16}{|l|}{$B$} \\
\hline \multirow[t]{2}{*}{7} & $\mathrm{~F}$ & $4 / 4$ & 3550 & 10 & & & Yes & abn & No & NA & & & & & $\mathrm{N}$ \\
\hline & $M$ & $2 / 6$ & $\mathrm{~N}$ & 3 & 25 & 10 & & $a b n$ & Yes & & & & & & $\mathrm{N}$ \\
\hline 8 & $\mathrm{~F}$ & $4.5 / 4.5$ & 3150 & 70 & 50 & 90 & No & $a b n$ & 2 & Yes & & & & & $t$ \\
\hline 9 & $M$ & $2.5 / 3$ & 3954 & $<5$ & 75 & 75 & No & $a b n$ & 3 & Yes & & & 33 & 26 & $\mathrm{~N}$ \\
\hline 10 & $M$ & $4 / 4$ & 2990 & $\mathrm{~N}$ & $\mathrm{~N}$ & $\mathrm{~N}$ & Noł & $a b n$ & 2 & Yes & fam & & 30 & 40 & id \\
\hline 11 & $M$ & $3 / 3$ & 4100 & $75-90$ & $10-25$ & $>95$ & No & $a b n$ & 3 & Yes & & & 31 & & $t$ \\
\hline \multirow[t]{2}{*}{12} & $\mathrm{~F}$ & $7.5 / 7.5$ & 2970 & $10-25$ & $90-97$ & 97 & 4.5 & $a b n$ & 2.5 & $\mathrm{~m}$ & & Yes & 43 & 45 & $\mathrm{~N}$ \\
\hline & $\mathrm{F}$ & $3 / 10$ & 3210 & $10-25$ & $10-25$ & $75-90$ & No & $a b n$ & 2.5 & No & & Words & 31 & 43 & $\mathrm{~N}$ \\
\hline 13 & M & $25 / 30$ & 3380 & 50 & 3 & 50 & 2 & $a b n$ & 2.5 & Yes & fam & No & 24 & 26 & $t$ \\
\hline 14 & $M$ & $2 / 3$ & 3460 & $<3$ & $<1$ & & & $a b n$ & 2.5 & Yes & fam & & 25 & 25 & $\mathrm{~N}$ \\
\hline
\end{tabular}

ID = under $\mathrm{A}$, patient identity number and under $\mathrm{B}$, reference number; $\mathrm{S}=$ sex; $\mathrm{AD}=$ age at diagnosis (in years); $\mathrm{R}=$ age at last review (in years); $\mathrm{BW}=$ birth weight (in grams); $\mathrm{HCR}=$ head circumference at last review; $\mathrm{HtR}=$ height at last review; $\mathrm{WtR}=\mathrm{weight}$ at last review; $\mathrm{E}=$ epilepsy with age of onset (in years) where applicable; $\mathrm{W}=$ age of walking alone (in years); $\mathrm{At}=$ ataxia; $\mathrm{P}=$ pigmentation; $\mathrm{SL}=$ sign language with number of words; $\mathrm{MA}=$ maternal age and $\mathrm{PA}=$ pateranl age at birth of the proband; $\mathrm{K}=$ karyotype; ${ }^{\star}=$ both parents tall; $\dagger=$ preterm; NA = not applicable; $N K=$ not known; $N D=$ not done; fam $=$ familial, namely pigmentation appropriate for the family; $\mathrm{H}=$ hypopigmented compared to the family; $\mathrm{abn}=$ abnormal; $\mathrm{m}=$ mild; $\neq=$ patient on anticonvulsant medication; $\mathrm{N}=$ normal; $\mathrm{t}=$ translocation; id $=\mathrm{inv} \operatorname{dup}(15)$. Information not filled in indicates that this feature was not mentioned in the published case reports. 


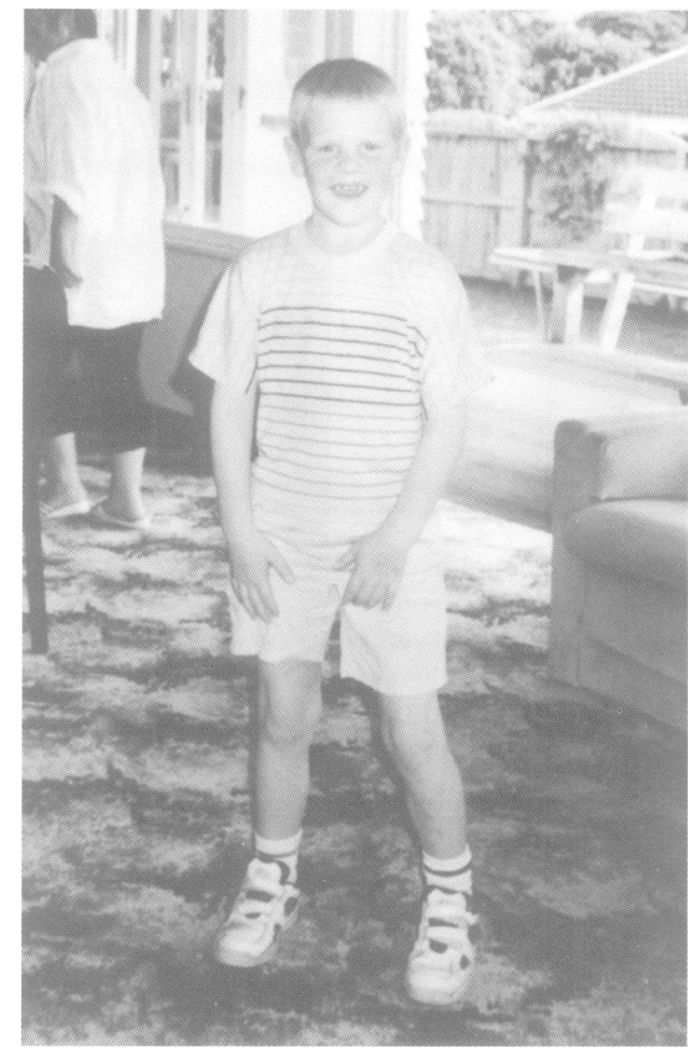

Figure 2 Patient 29 aged 8 years. Note the fair hair and white eyebrows.

gives overall $5 / 14(36 \%)$ of AS patients with UPD having a structural rearrangement involving chromosome 15(q11-13). This high frequency suggests that structural rearrangements of chromosome 15 predispose to malsegregation at meiosis. More detailed DNA studies on structural rearrangements of chromosome 15 in general are required to confirm this suggestion.

The observation that the AS phenotype can be influenced by the underlying genetic mechanism is of interest in the understanding of how imprinted genes are expressed. ${ }^{6}$ In PWS, valid comparative clinical data are scant but current evidence suggests that there are no differences in the phenotype of those with a deletion compared to those with UPD. ${ }^{19}$ Given that the size of the deletion in over $90 \%$ of PWS and AS patients is the same, ${ }^{6}$ it would appear that there is some fundamental biological difference in the expression of the imprinted gene(s) for PWS and AS.

Valid comparisons of the data presented here in 14 cases of AS resulting from UPD with AS

Table 3 Comparison of those features showing statistically significant differences between patients with AS owing to DNA deletion and those with UPD (in \%)

\begin{tabular}{llll}
\hline Feature & Deletion & UPD & $p$ value \\
\hline Microcephaly & 62.5 & 28.5 & 0.09 \\
Height < 3rd centile & 81 & 23 & 0.0064 \\
Weight > 50th centile & 15 & 64 & 0.073 \\
Seizures & -100 & 42 & 0.0056 \\
Walking by 3 years & 37 & 100 & 0.0063 \\
Hypopigmented & 73 & 25 & 0.042 \\
No/mild ataxia & 0 & 38.5 & 0.0048
\end{tabular}

* References 15, 20.

† Table 1 .

$\ddagger$ Application of the Fisher's exact test indicated wide confidence limits for each parameter with the limited information available.

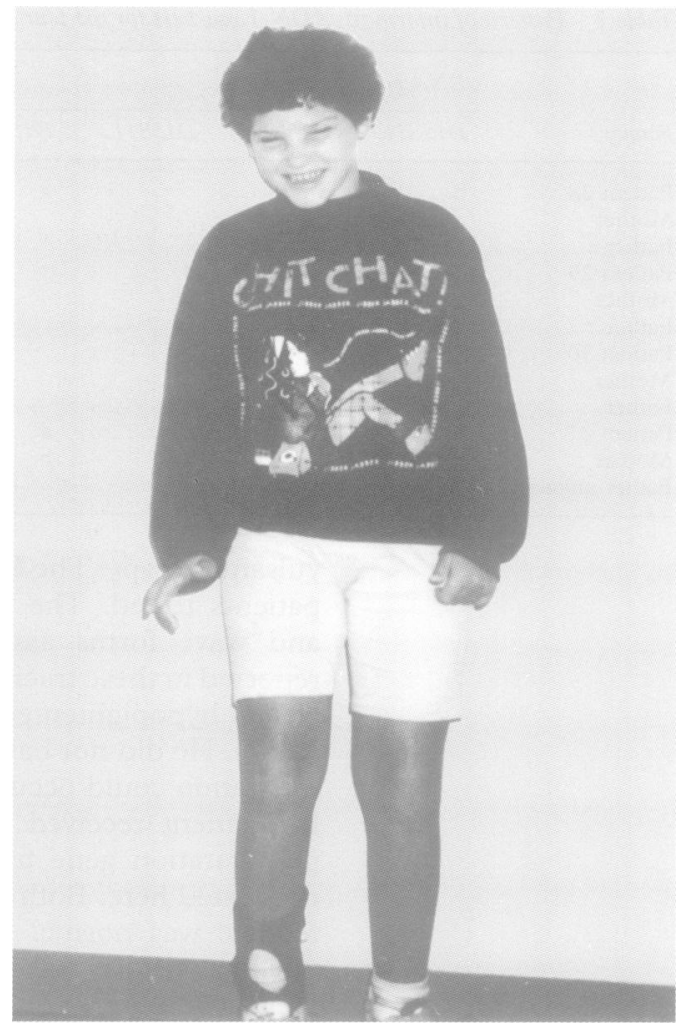

Figure 3 Patient 30 aged 11 years.

patients resulting from DNA deletion can be made (table 3 ). The deletional cases come from two surveys, 37 from Japan ${ }^{20}$ and 27 from Australasia. ${ }^{15}$ It appears that the facial phenotype is similar with all patients having a large mouth and chin, happy disposition, and outbursts of inappropriate laughter. There appear to be differences, however, in growth parameters and brain maturation (table 3 ). Growth in patients with UPD appears to be less retarded; these patients overall have a larger head circumference than those with deletion, weigh more, and are not as short. A higher level of brain function is manifest in the earlier age of onset of walking, milder ataxia, lower frequency of epilepsy, and greater ability to use sign language. Formal psychological testing of more cases is required to confirm the higher level of brain function suggested here. The implications of our findings for the diagnosis of AS are to broaden the guidelines for testing in patients suspected of AS and to test those who might be considered atypical by some physicians.

We thank Paul Oei, Cytogenetics Unit, Starship Children's Hospital, Auckland for providing cytogenetic metaphases from patient 31; Dr B Salmon, Waitemata Health, Auckland for arranging interviews and Sister S Muir for help with the interviews of patient 29; G Fairbrother, research officer, St George views of patient 29; G Fairbrother, research officer, St George
Hospital for help with the statistical analysis; Reckitt and Hospital for help with the statistical analysis; Reckitt and
Colman Pharmaceuticals for supporting AS research; and ProColman Pharmaceuticals for supporting AS research; and ProChildren's Hospital, Westmead for his support. The DNA work was performed under NH \& MRC Grant No 920303.

1 Angelman H. "Puppet" children: a report on three cases. Dev Med Child Neurol 1965;7:681-8.

2 Clayton-Smith J, Pembrey ME. Angelman syndrome. $f \mathrm{Med}$ Genet 1992;29:412-15.

3 Williams CA, Angelman $\mathrm{H}$, Clayton-Smith $\mathrm{J}$, et al. Angelman syndrome: consensus for diagnostic criteria. $\mathrm{Am}$ 7 Med Genet 1995;56:237-8. 
4 Clayton-Smith J, Webb T, Cheng XJ, Pembrey ME, Malcolm S. Duplication of chromosome 15 in the region $15 q_{11-13}$ in a patient with developmental delay and ataxia with similarities to Angelman syndrome. $7 \mathrm{Med}$ Genet 1993;30:529-31

5 American Society of Human Genetics/American College of Medical Genetics Test and Technology Transfer Committee. Diagnostic testing for Prader-Willi and Angelman syndromes: report of the ASHG/ACMG test and technology transfer committee. Am $\mathcal{F}$ Hum Genet 1996;58: 1085-8.

6 Nicholls RD. Invited editorial. New insights reveal complex mechanisms involved in genomic imprinting. Am f Hum Genet 1994;54:733-40.

7 Malcolm S, Clayton-Smith J, Nichols M, et al. Uniparental disomy in Angelman syndrome. Lancet 1991;337:694-7.

8 Smeets DFCM, Hamel BCJ, Nelen MR. Prader-Will syndrome and Angelman syndrome in cousins from a fam ily with a translocation between chromosomes 6 and 15. N Engl $\mathcal{F}$ Med 1992;326:807-11.

9 Nicholls RD, Pai GS, Gottlieb W, Cantu ES. Paternal uniparental disomy of chromosome 15 in a child with Angelman syndrome. Ann Neurol 1992;32:512-18.

10 Robinson WP, Wagstaff J, Bernasconi F, et al. Uniparenta disomy explains the occurrence of the Angelman and Prader-Willi syndrome in patients with an additional small inv dup (15) chromosome. Freeman SB, May KM, Pettay D, Fernhoff PM, Hassold TJ. Paternal uniparental disomy in a child with a balanced 15;15 translocation and Angelman syndrome. Am $\mathcal{F ~ M e d}$
12 Bottani A, Robinson WP, DeLozier-Blanchet CD, et al. Angelman syndrome due to paternal uniparental disomy of chromosome 15; a milder phenotype? $\mathrm{Am} \mathcal{F} \mathrm{Med}$ Genet 1994;51:35-40.

13 Smith A, Deng ZM, Beran R, Woodage T, Trent RJ. Familial unbalanced translocation $\mathrm{t}(8 ; 15)(\mathrm{p} 23.3 ; \mathrm{q} 11)$ with uniparental disomy in Angelman syndrome. Hum Genet 1994;93:471-3.

14 Gillessen-Kaesbach G, Albrecht B, Passarge E, Horsthemke $B$. Further patient with Angelman syndrome due to paternal disomy of chromosome 15 and milder phenotype. Am $\mathcal{F}$ Med Genet 1995;56:328-9.

15 Smith A, Wiles C, Haan E, et al. Clinical features in 27 patients with Angelman syndrome resulting from DNA deletion. F Med Genet 1996;33:107-12.

16 Deng ZM, Woodage TJ, Smart R, Smith A, Trent RJ. Novel patterns of inheritance of genetic disease are illustrated by the Angelman syndrome. Med f Austr 1993;158:813-16.

17 Boyd SG, Harnden A, Patton MA. The EEG in early diagnosis of the Angelman (happy puppet) syndrome. Eur $\mathcal{F}$ Pediatr 1988;147:508-13.

18 Robinson WP, Lorda-Sanchez I, Malcolm S, et al. Increased parental ages and uniparental disomy 15: a paternal age effect? Eur F Hum Genet 1993;1:280-5.

19 Robinson WP, Bottani A, Yagang X, et al. Molecular, cytogenetic, and clinical investigations of Prader-Willi syndrome patients. Am 7 Hum Genet 1991;49:1219-34.

20 Saitoh S, Harada N, Jinno Y, et al. Molecular and clinical study of 61 Angelman syndrome patients. Am $\mathcal{F}$ Med Genet 1994;52:158-63. 